\title{
Comentario
}

\section{La investigación acerca del usuario de la información}

工 as investigaciones bibliotecológicas y de la investigación gación principal: la información. Pero en esta última se encuentra el sujeto que la produce y la consume, por decirlo de esta forma, que es el llamado usuario de la información. Por lo tanto, la investigación que se lleva a cabo del sujeto, que bien puede ser el objeto, puede ir por diferentes vertientes, como por ejemplo investigar a este sujeto/objeto en su relación con diferentes comunidades, y por lo tanto en una gran diversidad de ellas entre las cuales se pueden mencionar algunas, como son: alumnos, docentes, agricultores, ganaderos, químicos, agrónomos, geógrafos, matemáticos, psicólogos, abogados y muchas otras más, todo dependerá de la forma de considerar a las comunidades de usuarios de la información conformados por diferentes características.

Pero también se puede ver otra vertiente que relaciona la forma de cómo el sujeto busca la información que necesita para desarrollar sus actividades y cumplir con su trabajo, su familia, su actividad dentro de la comunidad en la que vive o simplemente para engrandecer su propio conocimiento.

También la atención de una investigación puede centrase en la satisfacción informativa que siente un sujeto con respecto a las fuentes y recursos de información que utilizó para encontrar la información que necesitaba. En este aspecto el uso de las tecnologías de la información y la comunicación entra en juego como un medio para accesar a la información que necesitan las personas. Así la búsqueda de información que se hace desde los teléfonos celulares u otros dispositivos tecnológicos, por mencionar 
una de las posibilidades que lo permiten y utilizando un buscador como Google, lleva a un comportamiento de los usuarios que debe ser investigado para encontrar regularidades en sus comportamientos y en algún momento dado establecer patrones de ellos. Lo anterior con miras a poder facilitarles a los integrantes de las diferentes comunidades el acceso a la información que necesitan en el justo momento en que la requieren. Este aspecto se relaciona también con la libertad que cada ciudadano de un país democrático tiene con respecto al acceso libre a la información, sobre todo la académica y gubernamental.

Por lo anterior una investigación sobre el usuario de la información es muy amplia y si a esto se le añade lo que se quiere investigar en esa comunidad, como la necesidad de información, el comportamiento informativo o la satisfacción, entonces la riqueza de la investigación se transforma en algo con lo cual es posible elaborar marcos conceptuales y teóricos que puedan conformar modelos que permitan la descripción del fenómeno, y predecir lo que puede acontecer bajo ciertas condiciones y características.

Los modelos teóricos existentes sobre el fenómeno de las necesidades de información permiten investigar a los usuarios de la información y comprobar las variables involucradas en diferentes comunidades, y lo que se obtiene de estas investigaciones es precisamente un avance en el desarrollo de dichos modelos o en la creación de otros que se ajusten objetivamente a los hechos que explican el fenómeno investigado. Así con la conformación de estos modelos se puede conformar una teoría sobre el usuario de la información como el objeto mismo de la investigación bibliotecológica y de la información.

Ahora bien, el camino de la investigación para llegar a este punto es analizar los diferentes usuarios de la información en sus respectivas comunidades para obtener los datos necesarios que serán estudiados y observar las regularidades que están presentes en todo fenómeno social (como también ocurre con los fenómenos: físico, químico o biológico). El descubrimiento de estas regularidades permitirá enriquecer los modelos teóricos y por tanto llegar a la propuesta de fundamentos, principios y ¿por qué no? También de leyes.

En todo este contexto la investigación sobre los usuarios de la información llevará a seguir desarrollando la bibliotecología 
con base en uno de sus objetos de investigación y por tanto aportará conocimiento teórico aplicable.

Por otro lado las diversas comunidades de usuarios de la información que existen en México abren una amplia puerta a la investigación de aquellas, con el fin de poder delinear perfiles de usuarios de la información en cuanto a sus necesidades de información, su comportamiento informativo y su satisfacción informativa. Estos perfiles una vez descubiertos, analizados y estructurados permitirán aterrizar el diseño de servicios de información encaminados a cada una de estas diversas comunidades. Esto conlleva a permitir el acceso libre a la información que una comunidad necesita para poder resolver sus problemas de diferente índole. Así la satisfacción informativa de cada integrante de la comunidad permitirá que se desarrolle porque contará con la libertad de tener la información necesaria para resolver sus problemáticas individuales.

Entonces parte del desarrollo social implicará la libertad y dentro de ésta se podrá ubicar la libertad de acceso a la información para cubrir una de las necesidades de las personas que es la de información.

Garantizar la libertad de acceso a la información de los ciudadanos para cubrir sus necesidades informativas permitirá que el país se desarrolle en tanto que cada miembro de toda comunidad tendrá las "bases de información" que le permitirían elegir las acciones y decisiones necesarias en sus diferentes actividades que lleva a cabo como miembro de la sociedad. Esta libertad es propia de un país democrático y desarrollado, ya que si la libertad de contar con la información necesaria es coartada los ciudadanos no podrán cumplir con su parte dentro del desarrollo económico, educativo y social del país. De igual manera contar con la libertad de acceso a la información es la base para sustentar el comportamiento ético de una sociedad democrática, y de una sociedad participativa en todas aquellas acciones que le permitan su continuo desarrollo hacia mejores formas de estabilidad dentro de la convivencia pacifica en una sociedad desarrollada.

Por lo anterior, la investigación bibliotecológica y de la información, con respecto a una de sus partes que es la concerniente

1 El término "bases de información" está utilizado con esta finalidad en el capítulo tres de la obra de: Sen, Amartya Desarrollo y libertad. México: Planeta, 2000. 


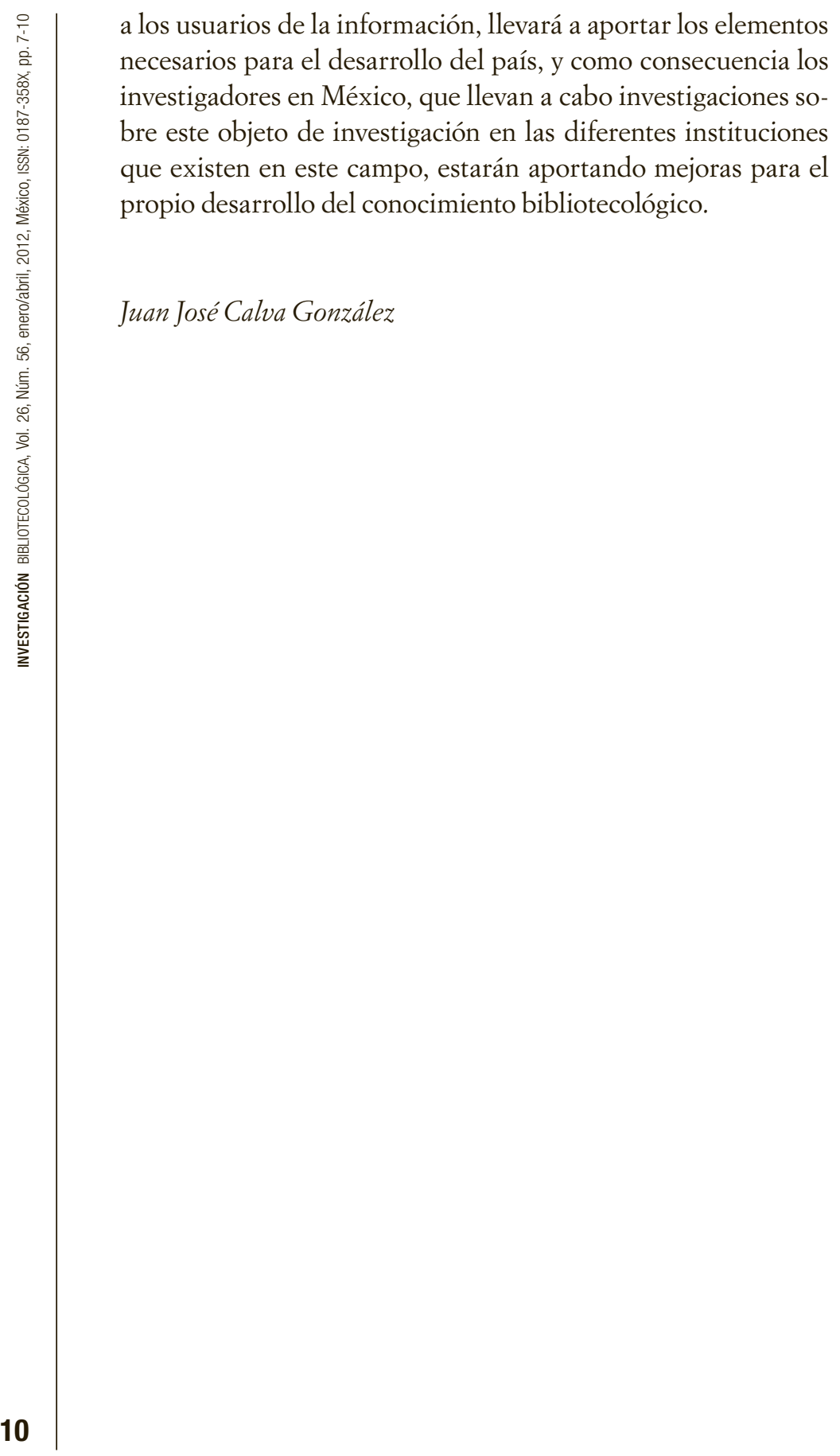

